\title{
Effects of stimulus duration on perceptual latency in the fovea
}

\author{
JOEL H. LEWIS, HALSEY H. MATTESON and WILLIAM P. DUNLAP \\ Tulane University, New Orleans, Louisiana 70118
}

\begin{abstract}
Perceptual latency to a foveal stimulus was determined with the perceived-order method. In Experiment 1, luminance ranged from 29 to 114,000 td, stimulus durations ranged from 2 to $2,500 \mathrm{msec}$, and all stimuli were $100 \%$ detectable. One observer showed no significant duration effect, and the other showed a significant, but irregular, effect. In Experiment 2, absolute threshold was determined at the same durations, and perceptual latencies were subsequently determined with luminance $.1 \log$ above absolute threshold $(100 \%$ detectable). Latencies increased at long durations for both observers. This result can probably best be explained in terms of probability summation.
\end{abstract}

Bloch's law states that the product of stimulus duration and luminance is constant at threshold. Complete intensity-time reciprocity holds up to a critical duration, and threshold luminance is constant (no reciprocity) for durations appreciably longer than critical duration. The transition to no reciprocity is usually gradual (Barlow, 1958; Graham \& Margaria, 1935; Karn, 1936; Sperling \& Jolliffe, 1965). Reaction time (RT) studies (Pease, 1964; Raab \& Fehrer, 1962; Sticht, 1969) found no effect of duration at moderate to high luminances; however, increased RT with decreasing duration occurred with low-luminance stimuli. Grossberg $(1968,1970)$ showed that increased RT with short-duration low-luminance stimuli is a result of less than $100 \%$ detectability.

The purpose of Experiment 1 was to study the effects of duration and luminance on perceptual latency with the perceived-order method (Alpern, 1954; Arden \& Weale, 1954). Although the comparison stimulus used in the perceived-order method adds complexity (i.e., experimental variables may affect the comparison as well as the test), this method does at least minimize decision-time and motor components inherent to RT. Since it is difficult to interpret perceptual latencies of stimuli which are not always detectable, the lowest luminance stimulus in Experiment 1 was $100 \%$ detectable even at the shortest duration.

The purpose of Experiment 2 was to determine the effects of stimulus duration on perceptual latency with the lowest consistently detectable luminance. Teststimulus luminance was set a constant ratio above absolute threshold, which should provide a reasonable

This paper is based on the first author's dissertation, which was performed in partial fulfillment of the doctoral degree at Tulane University. This work was supported by Grant EY00021 from the National Eye Institute, U.S. Public Health Service, to the second author. The data were presented at the annual meeting of the Optical Society of America, October 1974. The first author's current address is 2517 Governor Nichols Street, New Orleans, Louisianna 70119. approximation to equal brightness across durations. Studies using the perceived-order method and foveal stimuli have all found latency reduction with increasing luminance only up to $1 \log$ above absolute threshold. Studies with short-duration stimuli found small changes of latency (Alpern, 1954; Arden \& Weale, 1954; Matteson, 1971). Lewis, Dunlap, and Matteson (1972) found a large reduction of latency to the onset of a 5 -sec stimulus. Taken together, these studies tend to indicate that duration has a strong effect on latencies to low-luminance foveal stimuli.

\section{METHOD}

\section{Apparatus}

The three-channel Maxwellian view optical system was described previously (Matteson, 1969). Test and comparison stimuli were 30 -min circles. Observers fixated midway between two dim fixation lights which were $1 \mathrm{deg}$ apart vertically. The test stimulus was presented to the right eye, centered between the fixation lights. The comparison was presented $3 \mathrm{deg} 30 \mathrm{~min}$ below fixation in the left eye. White noise in earphones was used as a ready signal and to mask auditory cues. Noise onset was $1.5 \mathrm{sec}$ before test-stimulus onset and continued until after the observer responded. One male, J.L., and one female, J.S., were the observers. Both were 25 and had normal acuity with corrective lenses. J.S. was experimentally naive.

\section{Procedure}

With the perceived-order method, the observer reports which stimulus occurred first, the test or the comparison. In this study, observers based judgments on direction of stroboscopic motion. Points of subjective simultaneity were obtained using two intertwined staircase series (Cornsweet, 1962), with the two series one-half step apart. Latency was defined as test onset minus comparison onset. For example, a latency of $-75 \mathrm{msec}$ indicates that the comparison was presented $75 \mathrm{msec}$ before the test to obtain subjective simultaneity (i.e., the test was perceived $75 \mathrm{msec}$ before the comparison).

\section{EXPERIMENT 1}

Latency was obtained as a function of duration at four test-stimulus luminances: $29,90,921,114,000$ td. The eight durations were $2,4,8,16,32,64,128$, and 


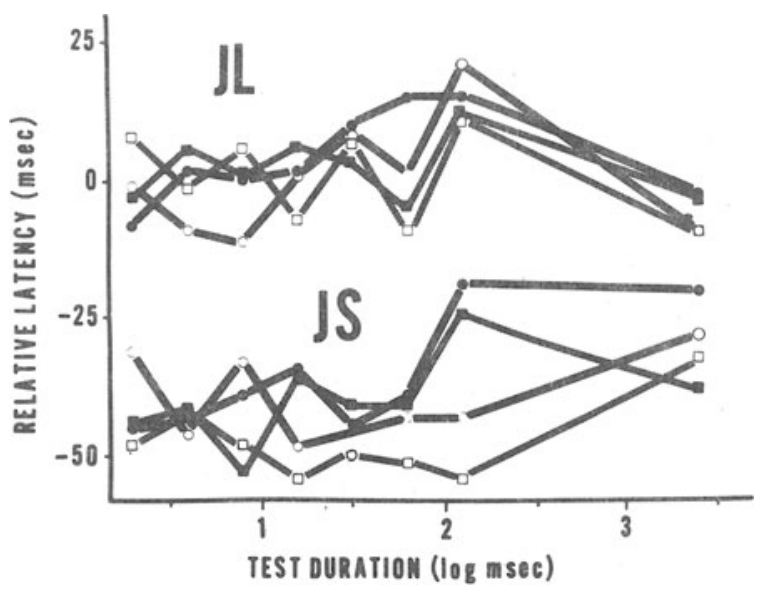

Figure 1. Perceptual latency as a function of test-stimulus duration with luminances of 29 (solid circles, solid line), 90 (open circles, solid line), 920 (solid squares, dashed line), and 114,000 td (open squares, dashed line). The top four curves were obtained from Observer J.L., and the bottom four were from J.S.

2,500 msec. At $2 \mathrm{msec}$, the 29-td test was approximately $.1 \log$ above absolute threshold and was $100 \%$ detectable. The luminance of the 5-msec comparison stimulus was 1,980 td. The experimental design was a luminance by duration by observers factorial with two replications. Two randomly chosen combinations of luminance and duration occurred in each session. Observers were given 2-min rests twice under each condition, and they had a 5-min rest between conditions. Each 50-min session started with a 20-min darkadaptation period.

\section{Results}

Latency is shown as a function of $\log$ stimulus duration in Figure 1. There was a small, but statistically significant $(p<.05)$, reduction of latency as luminance was increased. The main effect of duration was not statistically significant. Both observers showed little change of latency with increasing duration up to $64 \mathrm{msec}$. At durations longer than $64 \mathrm{msec}$, J.L.'s latency increased and then decreased, but J.S.'s latency increased slightly over the two longest durations. This discrepancy between observers (Observers by Duration interaction) was statistically significant $(p<.01)$; therefore, the data for each observer were analyzed separately. J.S. showed no significant effect of duration, but the main effect of duration was significant at the .01 level for J.L.

\section{EXPERIMENT 2}

Absolute threshold luminance was determined at each duration used in Experiment 1. Test luminance was set $.1 \log$ above each observer's threshold, which made all stimuli $100 \%$ detectable. Latency was then determined at each duration. In each case, the design was a duration by replications by observers factorial, and two replications were conducted. Both latency and threshold measures were obtained with the staircase method. Procedures were identical to those used in Experiment 1.

\section{Results}

Log threshold energy (I by $t$ ) is shown as a function of $\log$ duration in Figure 2A. Threshold critical duration for J.S. was $32 \mathrm{msec}$, but J.L.'s critical duration was at least $128 \mathrm{msec}$. The corresponding latencies are shown in Figure 2B. Relative latency was constant up to $16 \mathrm{msec}$ for both observers. For J.S., latency increased continuously from 16 to $2,500 \mathrm{msec}$. J.L.'s latency increased between 16 and $32 \mathrm{msec}$ and also increased between 128 and $2,500 \mathrm{msec}$; however, his shortest latency occurred at $64 \mathrm{msec}$. Since the Observers by Duration interaction was statistically significant $(p<.01)$, the duration main effects were analyzed

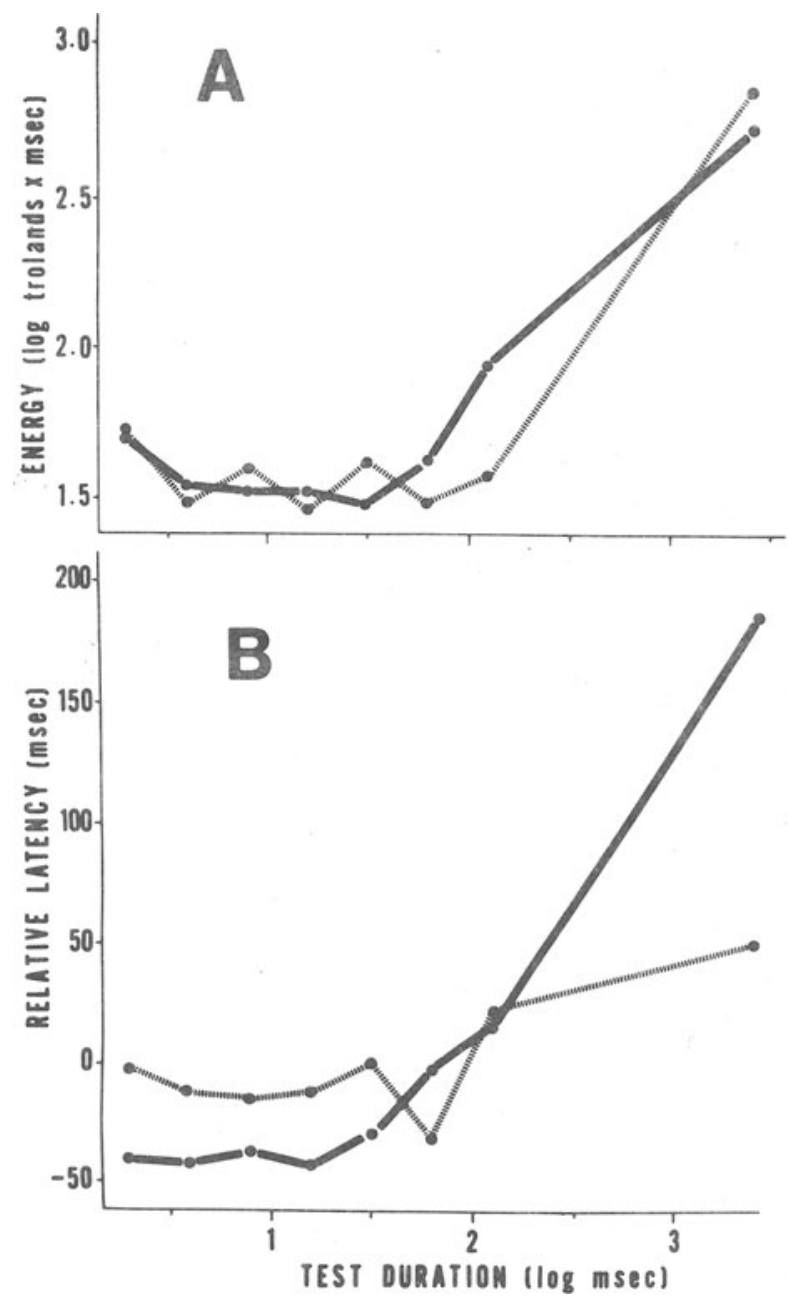

Figure 2. (A) Energy (trolands $X$ milliseconds) at absolute threshold as a function of test-stimulus duration. (B) Perceptual latency as a function of test-stimulus duration with test-stimulus luminance $.1 \log$ above absolute threshold. Solid lines represent data from J.S.; dashed lines represent J.L. 
separately for each observer. The duration main effect was significant in both cases (.05 level for J.L., .01 for J.S.).

\section{DISCUSSION}

The results of Experiment 1, which showed no consistent effects of duration, are in agreement with RT studies as long as RTs obtained with stimuli which are not always detectable are excluded. Pease (1964), Raab and Fehrer (1962), and Sticht (1969) found that foveal RT decreased with increasing duration with their lowest luminance stimuli, but RT was independent of duration at all higher luminances. As Grossberg (1968) suggested, increased RT with brief low-luminance stimuli is probably an artifact of detectability less than $100 \%$. RT to such stimuli may involve a decision-time component which is absent or negligible at higher luminances.

A gradual transition from complete intensity-time reciprocity to no reciprocity and a critical duration longer than $10 \mathrm{msec}$ for absolute threshold are typical with a stimulus as large as the one used in the present study (Barlow, 1958; Graham \& Margaria, 1935; Karn, 1936; Sperling \& Jolliffe, 1965). It is not unusual to find different critical durations with different response measures (Kahneman \& Norman, 1964). J.S.'s critical duration for perceptual latency was $16 \mathrm{msec}$, but her critical duration for absolute threshold was $32 \mathrm{msec}$. Since J.L.'s latency increased between 16 and $32 \mathrm{msec}$, it could be argued that his critical duration for latency was $16 \mathrm{msec}$, but his shortest latency occurred at $64 \mathrm{msec}$. J.L.'s critical duration for threshold was clearly at least $128 \mathrm{msec}$. It is possible that the irregularities in J.L.'s data might be due to difficulties in judging long-duration test stimuli relative to the $5-\mathrm{msec}$ comparison stimulus; however, a limited number of subsequent measurements showed no appreciable differences between latencies obtained with 5 -msec and 2.5 -sec comparison stimuli. At any rate, it seems that thresholds and latencies were mediated by different processes for both observers.

The increased latency in Experiment 2 is similar to increased RT obtained with long interflash intervals in two-flash RT studies (Grossberg, 1970, 1974; Pease, 1972). Pease suggested that energy in the two flashes summates to yield constant RT up to critical duration, but the energy in the first flash alone determines RT at long interflash intervals. Grossberg (1970), who found that RT to a pair of flashes sometimes exceeded RT to the first flash alone, suggested that increased RT might result from the observer responding occasionally to the second flash rather than to the first flash (probability summation). Peases's notion cannot explain the situation where RT to a pair of flashes exceeds RT to a single flash. Tolhurst (1975) explained RT to long-duration, high spatial frequency gratings in terms of probability summation. If it is assumed that longduration flashes are processed in successive intervals such as successive critical durations, then increased latencies with stimuli exceeding $16 \mathrm{msec}$ could probably be explained best with Grossberg's notion of probability summation.

In agreement with previous studies conducted with the perceived-order method in the fovea (Alpern 1954; Arden \& Weale, 1954; Matteson, 1971), the effect of luminance was small in Experiment 1. Between 29 and 114,000 td, J.L. and J.S. showed mean reductions of 4 and $12 \mathrm{msec}$, respectively. The only study which found extremely long foveal latencies with the perceived-order method used a long-duration test stimulus (Lewis, Dunlap, \& Matteson, 1972), and their conditions were similar to Experiment 2.

\section{REFERENCES}

Alpern, M. Relation of visual latency to intensity. American Medical Association Archives of Opthalmology, 1954, 51, 369-374.

Arden, G. B., \& Weale, R. A. Variations of the latent period of vision. Proceedings of the Royal Society (London), 1954, 142B, 258-267.

BARLOw, H. B. Temporal and spatial summation in human vision at different background intensities. Journal of Physiology (London), 1958, 141, 337-350.

Cornsweet, T. N. The staircase method in psychophysics. American Journal of Psychology, 1962, 75, 485-491.

Graham, C. H., \& Margaria, R. Area and the intensity time relation in the peripheral retina. American Journal of Physiology, 1935, 113, 299-305.

GrossBerg, M. The latency of response in relation to Bloch's law at threshold. Perception \& Psychophysics, 1968, 4, 229-232.

Grossberg, M. Frequencies and latencies in detecting twoflash stimuli. Perception \& Psychophysics, 1970, 7, 377-380.

Grossberg, M. Failure of Bloch's law for simple reaction time. Bulletin of the Psychonomic Society, 1974, 4, 147-149.

KaHneman, D., \& Norman, J. The time-intensity relation in visual perception as a function of the observer's task. Journal of Experimental Psychology, 1964, 68, 215-220.

KARN, H. W. Area and intensity-time relations in the fovea. Journal of General Psychology, 1936, 14, 360-369.

Lewis, J. H., Dunlap, W. P., \& Matteson, H. H. Perceptual latency as a function of stimulus onset and offset and retinal location. Vision Research, 1972, 12, 1725-1731.

Matteson, H. H. Effects of surround size and luminance on metacontrast. Journal of the Optical Society of America, $1969,59,1461-1468$.

Matteson, H. H. Effects of surround luminance on perceptual latency in the fovea. Journal of the Optical Society of America, 1971, 61, 1169-1172.

Pease, V. P. The intensity-time relation of a stimulus in simple visual reaction time. Psychological Record, 1964, 14, 157-164.

PEASE, V. P. Effect of luminance and duration of interstimulus interval on human reaction time. Journal of the Optical Society of America, 1972, 62, 1505-1507.

RAAB, D. H., \& FEHRER, E. The effect of stimulus duration and luminance on visual reaction time. Journal of Experimental Psychology, 1962, 64, 326-331.

SPERLING, H. G., \& Jolliffe, C. L. Intensity-time relationship at the threshold for spectral stimuli in human vision. Journal of the Optical Society of America, 1965, 55, 191-199.

STICHT, T. G. Effects of intensity and duration on the latency of response to brief light and dark stimuli. Journal of Experimental Psychology, 1969, 80, 419:422.

TolHurst, D. J. Reaction times in the detection of gratings by human observers; a probabilistic mechanism. Vision Research, 1975, 15, 1143-1149.

(Received for publication October 6, 1976.) 